\title{
EL SIGNIFICADO DE LA PALABRA \\ "SACRAMENTUM" EN EL PROCESO JUDICIAL ROMANO
}

\section{THE MEANING OF THE WORD "SACRAMENTUM"IN THE ROMAN JUDICIAL PROCESS \\ O SIGNIFICADO DA PALAVRA "SACRAMENTUM"NO PROCESSO JUDICIAL ROMANO}

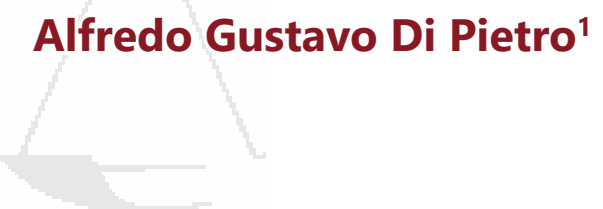

Licença CC BY:

Artigo distribuído sob os termos Creative Commons, permite uso e distribuição irrestrita em qualquer meio desde que $o$ autor credite a fonte original.

\begin{abstract}
Resumen: El significado de la palabra sacramentum es fundamental para comprender la relación entre los ritos y el derecho. La mayoría de los artículos especializados, procuran explicar el significado de la palabra sacramentum a partir de los textos de Lactancio. Sin embargo, el vocablo sacramentum, tiene un origen precristiano. En Instituta, Gayo menciona el sacramentum como una legis actio es decir una acción judicial de carácter general. Y dice que estas acciones eran acomodadas a las leyes -acommodatae erant-. Pero las leyes a las que se refiere Gayo deben ser entendidas en un sentido amplio, característico del pensamiento estoico. Así, el significado de sacramentum se vincula con la lex caelestis, con el vocablo sacrificium, y asimismo con el vocablo juramentum. Lactancio va a dar al vocablo sacramentum, un sentido cristiano. Tanto el sentido pagano del sacramentum, como el sentido cristiano, se van a mantener vigentes durante la edad media.
\end{abstract} (c) (i)

Palabras clave: Sacramentum, Legis actio, Sacrificium, Juramentum, Acommodatae erant.

Abstract: The meaning of the word sacramentum is essential for understanding the relationship between rites and law. Most specialized articles attempt to explain the meaning of the word sacramentum from the texts of Lactantius. However, the word sacramentum has a pre-Christian origin. In Instituta, Gaius mentions the sacramentum as a legis actio, that is, a general judicial action. And that these actions were accommodated to the laws -acommodatae erant-. But the words to which Gaius refers, must be understood in a broad sense, characteristic of Stoic thought. Thus, the meaning of sacramentum is linked to lex caelestis, with the word sacrificium, and with the word juramentum. Lactantius will give the word sacramentum a Christian meaning. Both the pagan meaning of the sacramentum and the Christian sense remained valid during the Middle Ages.

Keywords: Sacramentum, Legis actio, Sacrificium, Juramentum, Acommodatae erant.

$1 \quad$ Doctor en Ciencias Jurídicas por la Pontificia Universidad Católica Argentina "Santa María de los Buenos Aires". Decano de la Facultad de Ciencias Jurídicas de la Universidad Católica de Temuco, y Académico de Planta. Profesor en la Universidad de Buenos Aires, Enel Programa de Doctorado de la Universidad del Salvador y en la Universidad Nacional de José C. Paz. Dirección Postal: Manuel Montt 56, Temuco. Correo electrónico: adipietro@uct.cl. 
Resumo: O significado da palavra sacramentum é fundamental para entender a relação entre os ritos e o direito. A maioria dos artigos especializados procuram explicar o significado da palavra sacramentum a partir dos textos de Lactancio. Porém, a palavra sacramentum tem uma origem pré-cristã. Na obra Instituta, de Gaio, se menciona sacramentum como um legis actio, ou seja, uma ação judicial de carácter geral. Essas ações acomodavam as leis -acommodatae erant-. Mas as leis a que se refere Gaio devem ser entendidas num sentido amplo, característico do pensamento estoico. Sendo assim, o significado de sacramentum se vincula com a lex caelestis, com a palavra sacrificium, e da mesma forma com a palavra juramentum. Lactancio vai dar à palavra sacramentum um sentido cristão. Como no sentido pagão de sacramentum, como no sentido cristão, vão se manter vigentes até a Idade Média.

\section{Palabras clave: Sacramentum, Legis actio, Sacrificium, Juramentum, Acommodatae erant.}

\section{INTRODUCCIÓN.}

En los textos de Instituta, escritos por Gayo en el Siglo II de nuestra era, aparece la palabra sacramentum, cuyo origen se remonta a una época anterior a la Ley de las XII Tablas. Esta palabra, cuyo significado estuvo vinculado a la idea de rito jurídico, es pronunciada por Gayo con un sentido arcaico de acción judicial: actio generalis erat, aunque con la impronta propia de su época, para la cual el vocablo tuvo un significado mucho más profundo y extenso. Para el pensamiento estoico, al que Gayo adhería, la palabra sacramentum tiene un significado asociado al sacrificium, y al juramentum, con estrecha vinculación al orden cósmico y a la ley celeste.

Gayo describe al sacramentum como una legis actio, es decir como una de las acciones judiciales que estuvieron en uso entre los antiguos y que consistía en un rito o procedimiento del ius civile destinado a resolver controversias. Y expresa que estas legis actiones, recibían este nombre bien porque eran creadas por leyes o ya porque estaban ajustadas a las palabras mismas de las leyes y a causa de ello, eran observadas de manera inmutable al igual que las leyes. ${ }^{2}$ Si bien es cierto que algunas legis actiones habían sido establecidas por leyes, como es el caso de la condictio creada por las leyes Silia y Calpurnia, el sacramentum no parece haber tenido origen en ninguna ley, sino más bien en los mores maiorum. Por tal motivo, la expresión que utiliza Gayo: acommodatae erant, parece más bien referirse al caso del sacramentum, que resulta ser una legis actio, no por haber sido instituida por ley alguna, sino más bien, por resultar acomodada a las leyes.

Ahora bien, cuando Gayo expresa "acommodatae erant" cabe preguntarse ¿a qué leyes quiere referirse Gayo? La pregunta resulta significativa, pues en el derecho romano las leyes son escasas, y aun así los romanos no contaron con un sistema de derecho positivo como sucede en el mundo moderno. Por tanto, la respuesta a esa pregunta la podemos encontrar a partir de entender al vocablo lex no en un sentido restringido, como lex data o lex rogata, sino en un sentido amplio, como lex

2 GAYO, Instituta, Trad. Alfredo Di Pietro, Abeledo Perrot, 5ª Edición. 1997, pp. 631 y ss. 
caelestis, con especial referencia a las leyes de la naturaleza y del universo. Todo esto corresponde con la concepción estoica del mundo, que tanta influencia tuvo entre los juristas clásicos y a la cual Gayo tributaba de manera concreta.

\section{LOS ESTUDIOS SOBRE EL TEMA.}

El significado de la palabra sacramentum, ha sido esclarecido en la doctrina por diferentes trabajos que curiosamente no provienen tanto de los estudios sobre el derecho romano, sino más bien de la teología. Así podemos citar el estudio de Ghellinck "Pour l'histoire du mot Sacramentum" publicado en 1924 por la Université Catholique et Colleges Theologiques O.P. et S.J. de Louvain, así como el trabajo de G. Lebacqz "Les derniers Anténicéens". También merecen ser citados los artículos de Vincenzo Loi: "Per la storia del vocabolo Sacramentum: Sacramentum in Lattanzio, y "Il termine mysterium nella literatura latina prenicena" publicado en 1965 por la revista Vigiliae Christianae, y el artículo de Theodore Foster titulado "Mysterium and Sacramentum in the Vulgate and old latin versions", publicado en 1915 por The American Journal of Theology - The University of Chicago Press.

En general, estos estudios coinciden en concentrar toda la atención en los textos de Tertuliano y de Lactancio, y en la literatura cristiana posterior a estos autores.

J.P. Poukens S.J., con asiento en las Sententiae Episcoporum de Cypriano, y en textos anónimos, como los opúsculos De Pascha computus, De laude martyrii y Ad novatianum, entre otros, habla de un sentido dudoso de la palabra, y clasifica 116 ejemplos de posibles significados en tres grupos:

a) El sacramentum como juramento.

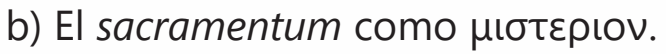

c) El sacramentum como signo.

Sin embargo, tales trabajos prestan poca atención al significado que este vocablo tenía en el mundo judicial romano, en donde la palabra ya era conocida, incluso en tiempos muy antiguos.

Van a ser los estudios de Lucién Levy Bruhl, en su obra "L'âme primitive", quienes van a señalar con mayor precisión la idea del sacramentum romano precristiano, y la relación que el sacramentum romano guarda con las leges, en un sentido muy amplio. ${ }^{<>}$

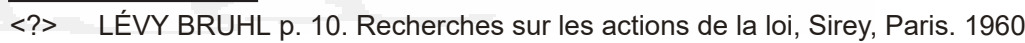


En la misma línea, caben mencionarse los trabajos de Georges Dumézil<?>, y de Mircea Eliade ${ }^{<?>}$.

Por lo tanto, dado que la palabra sacramentum es una palabra latina con significado propio, proponemos el desafío metodológico de conocer cuál es el significado atribuido a la palabra en el proceso judicial romano.

\section{EL TEXTO DE GAYO EN INSTITUTA IV-II-11.}

El texto que sometemos a análisis corresponde a Instituta, en donde Gayo, comienza a desarrollar el tema de las acciones judiciales. Probablemente, siguiendo un criterio histórico, donde empieza explicando las legis actiones, que corresponden con el procedimiento vigente durante el primitivo derecho romano.

El texto dice: Actiones, quas in usu ueteres habuerunt, legis actiones appellabantur uel ideo, quod legibus proditae erant, quippe tunc edicta praetoris, quibus conplures actiones introductae sunt, nondum in usu habebantur, uel ideo, quia ipsarum legum uerbis accommodatae erant et ideo immutabiles proinde atque leges obseruabantur.??

Y continúa en el párrafo siguiente: Lege autem agebatur modis quinque: sacramento, per iudicis postulationem, per condictionem, per manus iniectionem, per pignoris capionem.

Podríamos traducir el texto diciendo: Las acciones que estuvieron en uso entre los antiguos, se llamaban acciones de la ley, ya porque fueron creadas para ser leyes, pues en ese tiempo los edictos del pretor, por los cuales han sido introducidas la mayoría de las acciones no estaban en uso, ya porque estaban ajustadas -acommodatae erant- a las palabras mismas de las leyes y a causa de ello eran observadas de manera inmutable como las leyes. Por cinco modos se accionaba por la ley: por sacramentum, por iudicis postulatio, por condictio, por manus iniectio y por pignoris capio.

Entendemos que hay que tener en cuenta dos aspectos. El primero tiene que ver con la expresión acommodatae erant, para tratar de interpretar qué quiso decir el autor. En segundo lugar, resulta necesario precisar el sentido de la expresión immutabiles proinde. Estas son las dos cuestiones fundamentales que nos plantea el texto.

Para ello, resulta necesario indagar en los diversos significados que tuvo la palabra sacramentum en el mundo romano.

\footnotetext{
<?> DÚMEZIL 1966. La Religion romaine archaïque, avec un appendice sur la religion des Étrusques, Payot. Paris, 1966

$<$ ?> ELIADE M. Histoire des croyances et des idées religieuses, tome 1: de l'age de la pierre aux mystères d' Eleusis. Broché, Paris,1989

<?> GAYO, Instituta, Trad. Alfredo Di Pietro, Abeledo Perrot, 5ª Edición. 1997 p. 628.
} 


\section{EL SIGNIFICADO DEL SACRAMENTUM COMO IURAMENTUM.}

En el primitivo ius de los romanos, el sacramentum, o "Legis actio per sacramentum" fue el paradigma de rito jurídico de carácter general. Todo el ius primitivo tenía un carácter ritual, basado en la pronunciación de palabras. La "legis actio per sacramentum", en particular, comprendía toda una serie de ritos destinados a resolver litigios judiciales mediante la pronunciación de palabras ciertas y solemnes: certa et sollemnia verba. $<$ ?>

La palabra carmen, que podría traducirse como: verso, deriva de la raíz sánscrita kri, de donde proviene la voz karma, designa ante todo una acción ritual repetida constantemente de conformidad con rígidas reglas. ${ }^{<?>}$

Al respecto, G. Dumézil señala la vinculación de la expresión indoirania Yaus con el término latino lus, lo cual nos conducirá a lo que podemos establecer como el "sentido ritualista del ius", y que es la primera acepción de este vocablo. Si recordamos que existe una virtual sinonimia entre la palabra mos: costumbre y ritus: rito, tal cual lo podemos leer en Festus, cuando dice: ritus est mos comprobatus in administrandis sacrificiis <?> y también que se puede hablar de ritus, mos uel consuetudo -que señala la analogía idiomática entre dichos vocablos- agregando que rite autem significat bene ac recte $e^{<?\rangle}$, es decir, que los ritos están vinculados con lo bueno y lo recto $<$, , resulta comprensible que esos mores maiorum equivalentes a ritos de los antepasados, se practicaron regularmente en las gens.

Por lo tanto, entre sus diversas acepciones, la palabra sacramentum se utilizaba como la afirmación o juramento que realizaban ambas partes en el proceso. De allí, que Gayo mencione la idea de un falso sacramentum: "eaque actio proinde periculosa erat falsi sacramentum", al que tilda de peligroso. Otorgado por las partes ambos juramentos, la labor del iudex consistía en determinar cuál de los dos juramentos era iustum, y cuál iniustum, sin dar mayores explicaciones. Entre distintos autores, H. A. A. Danz, y P. F. Girard, también sostienen que el sacramentum, se trataba de un juramento pronunciado por las partes. Abona esta teoría, el texto de Festus en el que señala: "Se llama sacramentum aquello que se ha hecho por el iusiurandum, con la sacratio interpuesta".<?

\footnotetext{
<?> DI PIETRO Verbum luris. En el caso del sacramentum, no se hace sino cumplir con la regla religiosa de la escrupulosidad. Sabido es que en las legis actiones el juicio, o sea la resolución del diferendo estaba precedido de una serie de ritos consistentes en palabras y gestos que conformaban la legis actio propiamente dicha y lo más nutritivo del procedimiento, los cuales comportaban un acto teatral con netos ribetes religiosos. 1968. Pág. 45.

<?> $\quad$ DI PIETRO, Verbum luris, 1968 Pág. 60.

$<?>$ FESTUS, 364,34

$<?>\quad$ FESTUS, 337,4.

<?> DI PIETRO A. Ius Fasque Est. Revista Prudentia luris n I, Universidad Católica Argentina. Resulta sugestivo compararla con la definición de Celso: ius est ars boni et aequi, Dig., I, 1, 1, pr. 1980

<?> $\quad$ FESTUS, Sacramentum. "Sacramentum dicitur quod iusiurandi sacratione interposita factum est". asimismo: v. Sacramentum. "Qua de re lege L. Papirii trib. Pleb. Sactum est his verbis: Quicunque praetor post hoc factus erit, qui inter cives ius dicet, IIIviros capitales populum rogato, hique IIIviri quicunque posthac facti erunt, sacramenta ex igunto".
} 
Para ello debemos entender la gran importancia que para el pueblo romano tenían los juramentos. Así, se tomaban todo tipo de precauciones para no errar en el momento de proferir las palabras. Mientras un hombre pronunciaba la fórmula, otro se encargaba de ir siguiendo la dicción correcta de todas y cada una de ellas, y un tercero se encargaba de hacer observar el silencio, mientras se ejecutaba suavemente una melodía en la flauta para que ninguna otra palabra o ruido fuese escuchado, evitando que el rumor profano pudiese afectar el acto ritual.<?>

"Este sentido se ve por ejemplo en ciertas fórmulas religiosas donde el vocablo ius aparece relacionado con la divinidad. Debemos recordar para su comprensión que la religión romana está encarada dentro de un contexto de juridicidad, ya que las impetraciones realizadas bajo un esquema contractual del tipo "do ut des" -te doy para que me des-, con lo que, si se pide algo a los dioses (un favor, un beneficio, etc.) es porque al mismo tiempo se les da "algo", como contraprestación. Esto es lo que le corresponde a la divinidad y ello, con las fórmulas es llamado ius". "Así, encontramos en Catón:<?> "Si deus, si dea es, quium illum sacrum est, uti tibi ius porco piaculo facere illiusce sacri coercendi ergo harumque rerum ergo, siue ego siue quis iussu meo fecerit, util id recte factum siet..." ?> en la cual la divinidad es considerada propietaria del piaculum y la expresión tibi ius nos aclara el sentido de "ius", como "aquello que como divinidad, te corresponde", sacrificio que debe ser rectamente entregado uti id recte factum siet....

Igual ocurre en este otro párrafo, también de Catón: <?> "Iuppiter Dapalis, quod tibi fieri oportet, in domo familia mea culignam vini dapi, eis rei ergo macte hace illace dape pullucenda esto"<?> en la cual lo interesante es la expresión quod fieri tibi oportet-comenzando por aquello que a ti te debe ser dado-, señalándose con un verbo que será propio de la fórmula de la actio in personam (dare praestare facere oportere) la obligación que se tiene respecto de luppiter Dapalis, es decir, cumplir su ius, su pretensión máxima u óptima equivalente a pretensión debida, o que corresponde".

Del mismo modo, en el párrafo en el cual Aulo Gellio<?> se refiere a la captio vestalis: "Sacerdotem vestalem, quae sacre faciat, quae ius siet sacerdotem Uestalem facere pro populo Romano Quiritibus, uti quae optima lege fuit, ita te, Amata, captio"<?>. El sentido de "ius siet sacerdotem Uestalem facere pro populo Romano Quiritibus" debe ser entendido como el grado de competencia del actuar de la

$<?>\quad$ DI PIETRO A., Verbum luris, Ed. Abeledo Perrot. Citando a Plinio, Naturalis Historiae, XXVIII. 1968

$<$ ?> CATON, De agricultura, CXXXIX. Texte établi et traduit par R. Goujard. Ed. Les Belles Lettres, 1975

<?> La traducción sería así: "Seas un dios, seas una diosa, de quien es esta ofrenda, que consiste en hacerte el sacrificio de un puerco, que es "lo que te corresponde", resultando constreñido por ello, ya sea por mí o por quien por orden mía lo hiciere, que dicha ofrenda te deba ser rectamente entregada...".

$<$ ?> CATON, De agricultura, CXXXII Texte établi et traduit par R. Goujard. Ed. Les Belles Lettres, 1975

<?> "Júpiter Dapalis, por aquello que corresponda que se te deba dar, en mi casa y con mi familia, te ofrezco esta copa de vino, que te ofrendo ritualmente como comida en tu honor".

$<$ ?> AULO GELLIO, Noctes Atticae, I, 12, 14. Ed. Les Belles Lettres, Paris, 2002

$<$ ?> "Amada, te tomo como Vestal para que cumplas los ritos que debas hacer, y que te corresponde (ius siet) por el populus Romanus de los Quirites, conforme a la óptima lex". 
Vestal, "la máxima u óptima medida en que se debe cumplir la Vestal los ritos por el populus romanus de los Quirites".

\section{EL SIGNIFICADO DEL SACRAMENTUM COMO SACRIFICIUM.}

Para algunos autores, entre los que cabe mencionar a Noailles y a Lévy-Bruhl, el vocablo sacramentum, deriva de sacrificium, entendido como un sacrum-facere.

Desde un punto de vista etimológico, abona esta línea de interpretación, las correspondencias lingüísticas que encontramos en el idioma osco, en los vocablos sakoro, equivalente a sagrado, y sakrim a víctima del sacrificio.

Asimismo, esta hipótesis encontraría eco en la circunstancia según la cual, en un principio, el sacramentum romano comprendía el sacrificio de bestias, a las cuales se les examinaban las entrañas siguiendo una disciplina etrusca conocida como aruspicina.

Señala Gayo, que el sacramentum era una acción judicial de carácter general, y que por lo tanto se utilizaba en la gran mayoría de los casos.<?> En el rito, el actor, pronunciaba la expresión "sacramento te provoco", queriendo expresar así, que la cuestión iba a ser dirimida mediante este procedimiento ritual. El procedimiento ritual tenía inicio en la puerta de casa del demandado a quien el actor debía citarlo a juicio diciendo solemnemente: "in ius te voco", o "in ius ambula".

A partir de allí, una vez que ambas partes se encontraban presentes, procedían a efectuar un juramentum, mediante el cual cada uno de ellos fijaba su posición en el pleito, es decir que el actor afirmaba su reclamo diciendo: "Yo afirmo por este sacramentum, que tú, Ticio, me adeudas quinientos ases...", y el demandado confesaba o rechazaba la demanda.

En una ceremonia que se realizaba a la vera del río Tíber, junto al puente Sublicio, los arúspices procedían a sacrificar a los animales para examinar sus entrañas, especialmente el hígado, siguiendo prácticas que habían adquirido de los etruscos y eran conocidas como "aruspicina" o "etrusca disciplina". De tal modo, los pontífices resolvían las cuestiones judiciales, inclinándose en favor de uno u otro litigante.

Como señala Mircea Eliade, en las culturas antiguas, "El sacrificio tiene por objeto regenerar la totalidad del cosmos".<?>, y esta cercanía con el agua, tiene relación con el hecho de que las aguas representan la sustancia cosmogónica por excelencia.

<?> GAYO, Instituta, Trad. Alfredo Di Pietro, Abeledo Perrot, 5a Edición. 1997 IV, 13.

$<$ ?> ELIADE, M. Historia de las creencias y las ideas religiosas, Paidós Orientalia, Barcelona 2014, 288. 
Así, el sacrificio, tiene el sentido ya de purificar es decir llegar a un estado de pureza a partir de un estado vulgar dado a alguien, o a algo, o reparar purificando algo profanado por lo cual se restaura algo a partir de un estado impuro o enfermo.

"Esta salud o bendición tiene un sentido amplio, abarcando incluso un interés material, tal como se puede ver en el Rig-Veda<?> donde se pide a Rudra que dé la medicina para el "śám" y el "yóh", es decir el bienestar y la salvación. También se pide el "śám yóh" a las aguas pues son médicas muy maternales ${ }^{<?>}$ y asimismo se pide a los Marut que las aguas de la lluvia caída sean "śám yóh"<?>, es decir medicina saludable".<?>

Con posterioridad, y a partir de una iniciativa presentada por los cónsules Spurio Tarpeio y Aulo Aternio, el sacrificio de animales fue reemplazado por la entrega de una suma de dinero.

\section{EL SIGNIFICADO DEL SACRAMENTUM COMO DEPÓSITO.}

El sacramentum, también aparece vinculado a la suma de dinero en garantía que entregaban las partes en el procedimiento arcaico de las legis actiones. Esta suma era depositada por ambos litigantes, y quien resultaba vencido, debía ceder la suma de dinero a título de pena, la cual era finalmente entregada al populus romano ${ }^{<?>}$.

La pena prevista era de 500 ases o de 50 ases según el monto del juicio: "Poena autem sacramenti aut quingenaria erat aut quinquagenaria ... de minoris uero quinquaginta assibus sacramento contendebatur"<?>

La expresión sacramentum aes, según Gayo "Significa aquello que se pesa a título de pena, ya sea aquél que es interrogado, ya el que contendiera; en algunos asuntos es por 50 ases, en otros por 500, recíprocamente entre los que litigaran... Por el nombre de sacramentum se entiende hablar del dinero, el cual, a causa de la privación del erario, era consumido por la multitud en los asuntos públicos sagrados, es decir en las cosas divinas"'<?>

Varro, en el mismo sentido, dice que "si se trata de aquel dinero que se deposita ante la justicia en ocasión de un proceso, se denomina sacramentum". El demandante y el demandado, en

\footnotetext{
<?> RIG VEDA, II, 33. Hermann Grassmann, F. A. Brockhaus, Leipzig, 1877.

<?> RIG VEDA, II, 33. Hermann Grassmann, F. A. Brockhaus, Leipzig, 1877. VI, 50, 7

<?> RIG VEDA, II, 33. Hermann Grassmann, F. A. Brockhaus, Leipzig, 1877. V, 53, 14

$<$ ?> DI PIETRO A, lus Fasque Est. Revista Prudentia luris n I, Universidad Católica Argentina. 1980

<?> GAYO, Instituta Trad. Alfredo Di Pietro, Abeledo Perrot, 5a Edición. 1997, IV-14: summam sacramenti praestabat poenae nomine; eaque in publicum cedebat praedesque eo nomine praetori dabantur.

$<$ ?> GAYO, Instituta, Trad. Alfredo Di Pietro, Abeledo Perrot, 5a Edición. 1997, 4.14

<?> GAYO. Instituta, Trad. Alfredo Di Pietro, Abeledo Perrot, 5ª Edición. 1997, 4.14
} 
determinados litigios, depositaban ambos, quinientos ases de cobre en manos del pontífice; en otros casos, pleiteaban contra una cantidad de ases establecida por la ley. Quien ganaba el juicio retiraba el depósito o sacramentum que había entregado, mientras que el depósito de quien era derrotado era llevado al aerarium público.<?>

Sin embargo, una suma de dinero no puede tener nada de "sacrum", y es evidente el uso amplio del vocablo para designar todo aquello que de una u otra manera estaba vinculado con el rito.

\section{LA RELACIÓN ENTRE LOS VOCABLOS SACRUM Y SACRAMENTUM.}

Entre los asuntos divinos, es decir de la res divini iuris, existen tres conceptos fundamentales, que son el de lo sagrado, lo santo y lo religioso. Lo sagrado, está generalmente vinculado a un rito de dedicación, denominado consecratio. Lo santo, es lo esencialmente protegido o custodiado para evitar ser profanado, generalmente a través de la aplicación de una pena. Lo religioso, se halla vinculado al culto de los muertos, de los manes y a los sepulcros.

Mientras la res sacrae son las cosas que han sido consagradas, la res sanctae, son aquellas que se encuentran protegidas por una sanctio.

Y la res religiosae son aquellas que han sido relictas, es decir dejadas o abandonadas, como ocurre propiamente con los cadáveres.

Así, encontramos en Festo: "sacrum aedificium, consecratum deo, sanctum murum qui sit circum oppidum, religiosum, sepulcrum ubi mortuus sepultus aut humatus sit, satis constare..."<?>.

El sentido sagrado, se vincula con aquellas cosas que han sido consagradas públicamente, mientras que el de lo religioso, con el culto familiar y privado.

Por ello afirma Marciano diciendo: "son res sacrae las cosas que se han consagrado públicamente, y no en forma privada. Si alguno hubiere constituido privadamente como sagrada una cosa, esta no es sagrada sino profana"<?>.

La naturaleza de la consagración estaba muy en claro entre los escritores antiguos. Sobre los términos sacrum, sacrare, consecrare, nunca hubo disenso.

\footnotetext{
<?> VARRO: De lingua latina, V - 180. Anthropos Editorial del Hombre, Barcelona, 1990. 134, 135. "Si est ea pecunia quae in iudicium venit in litibus, sacramentum a sacro; qui petebat et quiinfitiabatur, de aliis rebus uterque quingenos aeris ad pontificem deponebant, de aliis rebus ítem certo alio legitimo número actum; qui iudicio vicerat, suum sacramentum e sacro auferebat, victi ad aerarium redibat".

<?> FESTUS, 287. Abrégé des Hauts faits du people romain. Ed, Les Belles Lettres, Paris 1994.

$<$ ?> DIGESTO I, 8, 6, 3. Corpus luris Civilis. Digestum Vetus seu Pandectarum luris Civilis cum Lectionum Florentinarum Varietatibus. Venetiis, apud luntas, 1589
} 
Para que algo sea tenido por sagrado, deben mediar: 1) la intervención autorizante del populus, mediante una ley, o del senado mediante un senado consulto. 2) una ceremonia ritual conocida como inauguratio, dedicatio o consecratio. En la que tomaban parte los pontífices. ${ }^{<>}$

Sin embargo, Hay dos palabras que se encuentran unidas, vinculadas. Esas palabras son la palabra inauguratio y la palabra consecratio. Una y otra están siempre presentes.

La inauguratio, comprende un conjunto de solemnidades que preceden al rito de la consecratio. Así, los augures, colegio sacerdotal dedicado a examinar la naturaleza para develar la voluntad de los dioses, examinaban tanto el cielo como el vuelo de los pájaros, y dictaminaban si el tiempo era propicio para realizar una acción determinada, diciendo fiat, en el caso que el augurio fuese favorable, o aliter dies, si no era el momento.

El hombre romano, que era eminentemente agricultor y por ello se sentía obligado a mantener una alianza con la tierra, se convirtió en un verdadero tutor de la naturaleza, es decir desarrolló una verdadera labor espiritual en la cual, ayudado por los numina deorum, coadyuvó a que la tierra diese los frutos de su seno. La tarea de fundar ciudades, como la de edificar templos, no era concebida como un trabajo autónomo, sino como la continuación del proceso creativo de la naturaleza, es decir como una sublimación de la agricultura. El resultado es la civitas que se presenta como un plus que el hombre agrega a esa natura ordenada y regida por la divina providencia. La civitas es el cosmos humano, esto es el todo organizado políticamente que se añade al cosmos natural, como una expresión glorificada de aquél.

Cuando el alto magistrado de la ciudad, asistido del pontifex dedicaba una construcción como templo de una divinidad, no se limitaba a pronunciar la lex dedicationis, sino que además debía tocar con sus manos las puertas del templo. Cuando el imperator quiere dedicar a Júpiter y a los manes el ejército enemigo, y pronuncia el nombre de la diosa Tellus, toca con sus manos la tierra, y cuando pronuncia el nombre de Júpiter, alza sus ojos al cielo. <?>

De ello se desprende que el nomen, cuando es pronunciado, evoca un numen determinado. El nomen permite adentrarse en el mysterium rerum, que nos permite revelar lo divino que habita en la realidad. Y así, la pronunciación de palabras ciertas y solemnes estaba destinada a recrear el ámbito de lo sagrado para conocer el ius en el caso concreto y reestablecer el orden cósmico que ha sido afectado.

$<$ ?> OVIDIO, Les Fastes. 610. Ed. Les Belles Lettres., Píndaro, Fragmentos. 1993

$<?>\quad$ DI PIETRO, Alfredo. Verbum luris. Ed. Abeledo Perrot. 1968 


\section{EL SACRAMENTUM COMO AFIRMACION DEL ORDEN UNIVERSAL}

La expresión de Gayo: acommodatae erant, debe interpretarse correlativamente con las leyes celestes, es decir con las leyes que rigen el cosmos según la filosofía estoica.

Como ya indique en mi libro sobre la cuestión de los derechos subjetivos en el derecho romano: ${ }^{<?>}$ "El pensamiento estoico, para el cual, ninguna de las cosas singulares, ni las especies animadas tiene existencia solamente "per se", sino que existen con referencia a las demás cosas, a fin de integrar en su correlación, la idea del orden cósmico, del mismo modo como las líneas, los colores y las formas proporcionadas de un cuadro no valen tanto por su individualidad como por su integración pictórica. Así como el cofre está hecho para el collar y la vaina para la espada, así, salvo el mundo, todo ha sido creado con referencia a otra cosa; por ejemplo, el trigo y los frutos producidos por la tierra en vista de los animales, y los animales en vista del hombre; el caballo para transportarlo, el buey para trabajar, el perro para la caza y la guardia".<?

Frente a esta natura organizada y regida por la res publica deorum, se encuentra el hombre, ese ser mediador entre el cielo y la tierra, ${ }^{<?>}$ que ha sido creado con una figura enhiesta sobre el suelo, la talla alta y derecho, de tal modo que mirando al cielo pudiera tener conocimiento de los dioses. ${ }^{<>}$

Para él ha sido creado el mundo, y todo lo que se halla en él. En cierto sentido, es el operario que los dioses han puesto sobre lo creado para perfeccionar el orden inmanente del cosmos.

Instituido para cultivar la tierra, no permite que ella quede en el estado salvaje por la acción de las bestias feroces, o devastada por los matorrales; por sus cuidados resplandecen los campos, las islas, las riberas, se levantan las casas y las ciudades. ${ }^{<?>}$

El hombre romano, que era eminentemente agricultor y por ello se sentía obligado a mantener una alianza con la tierra, no encaró sin embargo la labor agrícola como una mera explotación económica, sino que se convirtió en un verdadero tutor de la naturaleza, es decir desarrolló una verdadera labor espiritual en la cual, ayudado por los numina deorum, coadyuvó a que la tierra diese los frutos de su seno.

<?> DI PIETRO, Alfredo. La cuestión de los derechos subjetivos en el derecho romano. Colección Estudios Jurídicos. Ediciones Universidad del Salvador, 2013. ISBN 978-950-592-166-9, Buenos Aires, Argentina.

<?> CICERON, De natura deorum, II, XIV, 37, citando a Chrissipo. Ediciones UNAM, Centro de Estudios Clásicos, Instituto de Investigaciones Filológicas, Universidad Nacional Autónoma de México, 1976.

<?> CICERON. De natura deorum, II, XXXI, 78. Ediciones UNAM, Centro de Estudios Clásicos, Instituto de Investigaciones Filológicas, Universidad Nacional Autónoma de México, 1976.

<?> CICERON. De natura deorum, II, LVI, 140. Ediciones UNAM, Centro de Estudios Clásicos, Instituto de Investigaciones Filológicas, Universidad Nacional Autónoma de México, 1976.

<?> CICERON, De natura deorum II, LX, 150. Ediciones UNAM, Centro de Estudios Clásicos, Instituto de Investigaciones Filológicas, Universidad Nacional Autónoma de México, 1976. 
Además, en esa visión netamente espiritual, y como una expresión superior de la "cultura", emprendió la tarea de la fundación de ciudades, no como una labor separada y autónoma, sino como la continuación del proceso creativo de la naturaleza, es decir como una sublimación de la agri-cultura. El resultado es la civitas que se presenta como un plus que el hombre agrega a esa natura ordenada y regida por la providencia divina. La civitas es el cosmos humano, esto es el todo organizado políticamente que se añade al cosmos natural, como una expresión glorificada de aquél.

Tenemos pues, el ordo naturalis y, además, el ordo civitatis. El primero se encuentra regido por la inquebrantable ley divina, la cual, en su ámbito, se prolonga en el ius. ¿?> De este modo, el segundo orden resulta también inscripto en la esfera de aplicación de la lex naturae. Además, el ius necesita, por razón de su especificidad, reglas propias de cada civitas ${ }^{<?>}$. Aparece así la idea de ius civile -derecho positivo-, frente al ius naturale. Es claro que, siendo las reglas de aquel orden establecidas por los hombres, éstas pueden ser justas, pero también injustas, ya que corren el riesgo de la falibilidad de la razón. Pero dada la interrelación de ambos órdenes, "para distinguir una ley buena de una mala, nosotros no tenemos - dice Cicerón- otra regla que la naturaleza. "Y la naturaleza nos hace distinguir lo justo de lo injusto de una manera más general, pues distinguimos las cosas moralmente bellas de aquéllas que son feas, y una especie de inteligencia expandida por todas partes nos la hace conocer e inclina nuestras almas a identificar las primeras a las virtudes, las segundas a los vicios".<?>

El sentido originario de la lex naturae en relación con la ley humana, lo podemos advertir, por ejemplo, en las palabras que el dictador Camillus dirige a sus soldados, a propósito de la deserción de uno de los faliscos: "No existen entre nosotros y los faliscos, los vínculos que resultan de una convención humana; pero sí aquéllos que la naturaleza hace nacer tanto entre nosotros como entre ellos, que existen y que existirán. Hay un derecho de la guerra como de la paz, y nosotros hemos aprendido a respetar este derecho no menos que a combatir con coraje".<?>

Este sentido estoico de prevalencia de la lex naturae, así como de la conformidad que debe existir entre la lex humana y la natura, se puede advertir igualmente en el siguiente párrafo de Celso: Qui rerum natura prohibentur, nulla lege confirmata sunt, esto es que debe existir concordancia entre la "natura" y la "lex", pues de lo contrario, la norma que se opone a este principio resulta indefectiblemente nula. Esto es de un todo perfectamente organizado donde todas y cada una de las cosas y seres componen un orden perfecto, regulado por una justicia inquebrantable, el hombre

\footnotetext{
<?> CICERON, De Legibus II, Ed. Les Belles Lettres, Paris, Texte établi et traduit par G. de Plinval. 1959. 5, 13.: "Ergo est lex iustorum iniustorum que distinctio ad illam antiquissimam et rerum omnium principia expressa naturam, ad quam leges hominum deriguntur, quae supplicio improbos adficiunt, defendunt, actuentur bonos".

<?> GAYO, Instituta, I, 1: "Omnes populi, qui legibus et moribus reguntur, partim suo propio, partim communi omnium hominum iure utuntur: non quod quisque populus ipse sibi ius constituit, id ipsius proprium est vocaturque ius civile, quasi ius proprium civitatis".

$<$ ?> CICERON, De Legibus I, 15, 44. Ed. Les Belles Lettres, Paris, Texte établi et traduit par G. de Plinval. 1959.

<?> TITO LIVIO, V, XXVII, 6. Ab urbe condita. Texte établi et traduit par Paul François. Ed. Les Belles Lettres. 2003
} 
romano conoció esta idea, en una primera época de una manera no tan clara y definida, pero que luego, va a expresar en el concepto de naturae.

Cuando uno lee, por ejemplo, la maravillosa descripción que Cicerón hace de la naturaleza en ese verdadero opúsculo de -si es que cabe la expresión-, teología estoica, que es el Libro II de su De natura deorum, se percata de la "vista de todas esas cosas que demuestran por sí mismas que no son debidas al azar". Ello hace sentir al filósofo un sincero goce de fruición ante esa "regularidad del movimiento, la revolución del cielo, la distinción entre el sol, la luna y todas las estrellas, su utilidad, su belleza, su orden".

Para el hombre común, el hábito cotidiano es el que le impide la admiración del orden del cosmos, puesto que no se asombra más; no busca las razones de las cosas que está continuamente viendo, como si la novedad de los objetos más que su importancia fuera la que correspondiera obligarnos a inquirir sus causas.

Pero en cuanto nos detenemos a pensar sobre este orden, cuánta es la belleza que se nos ofrece: "Considerad ante todo la tierra entera, colocada en el centro del mundo, sólida, esférica, reuniéndose por todas partes sobre ella misma por el efecto de su gravitación, revestida de flores, de hierbas, de árboles, de cosechas, cuya increíble multitud se distingue con una insaciable diversidad. Agregadle el frescor de las fuentes inagotables, la limpidez de las flores, el ornato verdeante de los ríos, la profundidad de las cavernas, la preeminencia de los riscos, la altura de las montañas que nos dominan, la inmensidad de las llanuras; agregadle aún los filones escondidos de oro y plata y la cantidad infinita de mármol. ¡Cuántas especies variadas de bestias domésticas o salvajes! ¡cuántas clases de vuelos, cuántos cantos de pájaros! cuántos pastizales para los ganados! ¡Qué animación hay en los bosques!<?>

Incluso ese criterio jerárquico, queda extendido a la propia conformación humana: "Por qué Dios ordena al hombre, el alma al cuerpo, la razón al apetito sensual, a la cólera y a las otras partes viciosas del alma".<?

Todos, pues, y cada uno de los seres, ocupan el lugar que les corresponde, es decir, tienen su status dentro del cuadro genérico -ex coherentibus- de la naturaleza, que somete a los más débiles al cuidado de los mejores, todo ello de acuerdo al plan organizado por la divinidad, pues ella es quien la gobierna.

<?> CICERON, De natura deorum, II, XXXIX, 98-99. Ediciones UNAM, Centro de Estudios Clásicos, Instituto de Investigaciones Filológicas, Universidad Nacional Autónoma de México, 1976.

<?> CICERON, De Re Publica.III,24; Ed. Les Belles Lettres, Paris, Texte établi et traduit par Esther Bréguet. 1980. San Agustín, De Civitate Dei, $19-21$. 
Esa voluntad divina es entrevista como un ser unitario cuando se refiere a luppiter, el supremus rex <?>, qui omnem mundum regit <?>, diuonque hominumque pater rex <?> mortalis atque urbes belluasque omnis iuvat. .?> $^{\text {? }}$

Para la guarda de este orden, la natura tiene su ley inmanente que preserva la justicia inquebrantable de las cosas. Esa es la lex caelestis, es decir, aquella que está prescripta por los dioses, y de la cual, poéticamente, en el pensamiento griego, dijo Sófocles que se trata de "leyes sublimes, prohijadas en el Éter celeste: es el Olimpo su único padre; la naturaleza mortal de los hombres no la ha producido; jamás el olvido las dejará dormir; un gran dios está en ellas y este dios no conoce la vejez"<?>.

Píndaro la proclama como "la reina que rige el todo y todas las cosas", es decir la que prescribe el papel que le corresponde jugar a cada uno. ${ }^{<?>}$ Este último párrafo tiene importancia por cuanto es recordado nuevamente por Chrissipo: "philosophus sumae stoicae sapientiae", cuando en texto que integra uno de los párrafos del Digesto, dice: "Lex est omnium divinarum et humanarum rerum regina". Nada escapa de ella, hasta tal punto que el obscuro Heráclito puede decir muy sabiamente en un fragmento de su obra que "el sol no traspasará sus medidas; de lo contrario, las Erinnias, ministras de Diké, sabrán encontrarlo".

Esta es la ley natural a la cual Cicerón llama "ratio summa insita in natura", "vera lex, recta ratio, natura congruens, diffusa in omnes, constans, sempiterna", "recta ratio summi lovis", significando lo "aeternum quiddam quod universum mundo regeret...lex quam dii humano generi dederunt".

Es esa la ley natural a la que se refieren -bajo otro aspecto- el jurista Ulpiano cuando habla del "ius naturale", Gayo cuando nos refiere el fundamento de la "naturalis ratio", y también Paulo cuando expresa el primero de los sentidos del vocablo "ius" como "quod semper aequum ac bonum est".

Esa ley a la que canta Cleanthes como capaz de dar una noble vida a aquellos que la sigan inteligentemente y que le hace decir en el final de su himno a Zeus, como verdadera expresión poética y religiosa de la fe estoica: "Salva a los hombres de la malhechora ignorancia, disípala, oh Padre, lejos de nuestra alma, déjanos participar en esta sabiduría sobre la cual tú te fundas para gobernar todas las cosas con justicia, a fin de que honrados por ti, nosotros podamos recíprocamente honrarte,

\footnotetext{
<?> PLAUTO, Anfitrión. Traducción Gregorio Hinojo. Espasa Calpe, 1991, 831.

<?> CICERON, De Re Publica.VI, 13,13. Ed. Les Belles Lettres, Paris, Texte établi et traduit par Esther Bréguet. 1980.

<?> ENNIUS, in Varro, De Lingua Latina, V, 65. Editorial Anthropos, Editorial del Hombre, Barcelona. 1990.

$<$ ?> VARRO, De Lingua Latina, V,65. Editorial Anthropos, Editorial del Hombre, Barcelona. 1990.

$<$ ?> SOFOCLES, Edipo Rey, 865 y ss. Paris, Les Belles Lettres 1958

<?> PÍNDARO, Fragmentos, 169. Sobre el mismo y evolución del concepto de "nomos", ver Heinemann F., Nomos und Physis, Basel, 1965.

<?> DIGESTO. I. I. 11. Digestum Vetus seu Pandectarum luris Civilis cum Lectionum Florentinarum Varietatibus. Venetiis, apud luntas, 1589
} 
cantando continuamente tus obras, como le cabe a los mortales; pues no hay nada para los hombres o los dioses de más alto privilegio que cantar por siempre, como se debe, a la ley universal".<?

Desde esta perspectiva, los ritos jurídicos conocidos como legis actiones, entre los cuales se encuentra el sacramentum, resultan acomodados a esas leyes universales.

\section{EL NUEVO SIGNIFICADO DEL SACRAMENTUM A PARTIR DE LOS TEXTOS DE LACTANCIO.}

A partir de los textos de Lactancio, el sacramentum se va a identificar con la idea griega de "misterio". Probablemente, encontró en el vocablo sacramentum, un término compatible con el misterio cristiano, en un sentido que para el pueblo romano resultara comprensible.

Así expresa Lactancio, tras citar un pasaje de Cicerón sobre la ley verdadera, su asombro ante el hecho de que éste se exprese tan acertadamente sin conocer el misterio de Dios: "quis sacramentum Dei sciens, tam significanter enarrare legem Dei posset, quam illam homo (Cícero) longe a veritatis notitia remotas expressit"

Lactancio va a emplear el vocablo sacramentum, asimismo, en muchos otros sentidos.

Como señala Lourdes Martín-Albo Huertas en su brillante tesis doctoral, "Podemos poner este término en relación con otros tres de sentido parecido, usados asimismo por Lactancio: mysterium, arcanum y sacrarium. Estos tres vocablos, junto con sacramentum, parecen tener, en general, el mismo sentido, ya que todos aluden principalmente al misterio de Dios y de su religión, si bien encontramos rasgos propios del significado de cada uno de ellos".<?>

Aquí, Lactancio utiliza el vocablo "sacramentum" tanto con sentido pagano como cristiano. Con sentido pagano, lo emplea por ejemplo en II, 9, 21, cuando denomina al matrimonio como un "sacramenta ignis et aqua nuptiarum".

De todas maneras, el vocablo va a adquirir un sentido nuevo, que va a ser aquél con el que se lo va a emplear en el lenguaje cristiano posteriormente.

Por ello encontramos en San Agustín: "Hoc est sacrificium Christianorum: multi unum corpus in Christo. Quod etiam sacramento altaris fidelibus noto frequentat ecclesia, ubi ei demonstratur, quod in

\footnotetext{
$<?>\quad$ CLEANTHES, Himno a Zeus, Les stoiciens, La Pleiade, pág. 6-7.

$<$ ?> $\quad$ LACTANCIO, Instituciones Divinas, Editorial Gredos. Madrid. 1990 p. 203.

<?> MARTIN-ALBO HUERTAS L. Latín pagano, lengua de cristianos. Cristianización del léxico en las Divinae Institutiones de Lactancio. Tesis doctoral, 253
} 
ea re, quam offert, ipsa offeratur. ${ }^{<?>}$

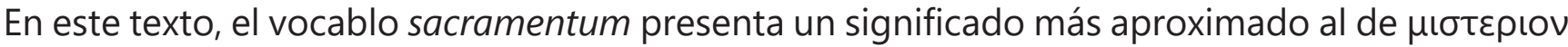
griego, entendido en el contexto de la nueva religión cristiana, en la que el sacramentum se presenta como un signo eficaz de la gracia divina.

Cabe presumir que los primeros cristianos encontraron en el vocablo sacramentum, la palabra más aproximada a lo que ellos querían significar como afirmación o unión a la realidad divina, y dieron un nuevo contenido a un término evidentemente arraigado en las tradiciones latinas, y de profundo significado.

Por otra parte, el sentido del "Sacramentum" se va a mantener en la Europa medieval, con el sentido de "juramentum".

El caso más evidente del empleo de la palabra con este sentido, lo encontramos en los llamados juramentos de Estrasburgo, más bien conocidos como sacramenta argentariae, que datan del año 842 , en los cuales se utiliza el vocablo "sacramentum", en el sentido de "juramentum".

Estos juramentos, de gran importancia lingüística fueron redactados en lengua tudesca y protofrancés, y dicen: "Si Lodhuuigs sagramento, que son fradre Karlo iurat conseruat ..."

La importancia de este texto es fundamental, pues revela que el sentido del sacramentum pagano va a subsistir durante mucho tiempo, y va a coincidir con el cristiano, especialmente a lo largo de toda la edad media.

Expresa, asimismo, que la palabra sacramentum tiene un significado general, y abarca múltiples situaciones en las que el elemento común es la vinculación del hombre con las realidades divinas.

\section{CONCLUSIONES.}

El conocimiento del significado de la palabra sacramentum, es fundamental para comprender la relación entre los ritos y el derecho.

Los estudios especializados sobre el significado de la palabra sacramentum, suelen partir de los textos de Lactancio, escritor y retórico de fines del siglo III, que dio a la palabra un significado cristiano. Sin embargo, la palabra sacramentum tiene un origen y un significado mucho más antiguo, que se remonta a una época anterior a la Ley de las XII Tablas, y corresponde con las tradiciones del pueblo romano. La cuestión reviste especial importancia para entender el origen de los procedimientos judiciales y asimismo para el derecho canónico.

<?> AGUSTIN DE HIPONA: De Civitate Dei, X, VI. Nótese que San Agustín emplea el vocablo Sacramentum como Sacrificium: "Éste es el sacrificio de los cristianos: unidos a Cristo formamos un solo cuerpo Éste es el sacramento tan conocido de los fieles que también celebra asiduamente la Iglesia, y en él se le demuestra que es ofrecida ella misma en lo que ofrece". 
En Instituta IV-II-12, Gayo menciona el sacramentum como una Legis actio, es decir como un rito jurídico de carácter general, siendo ésta la primera acepción del vocablo, pues en la administración de justicia, cuando por la ley no estaba previsto de qué modo se debía accionar, se recurría a este sacramentum. Este va a ser el eje de todo el primitivo procedimiento judicial romano.

En Gayo, también el vocablo es utilizado con un sentido de "depósito", pues en el procedimiento más antiguo, las partes debían entregar un animal -que luego fue reemplazado por la entrega de una suma de dinero-. Aquél que resultaba vencido en el litigio, perdía el depósito, que era derivado al aerarium, y el vencedor, recuperaba la suma depositada. Esta acepción se halla presente en los textos del propio Gayo, en los que se habla, por ejemplo, de "...un sacramentum de 50...", dando nombre el vocablo, a la suma que se deposita.

El sacramentum, es propiamente una legis actio, es decir, un rito judicial. Según Gayo, las Legis actiones recibían esta designación por dos razones: porque fueron creadas por leyes, o porque eran acomodadas a las leyes. Esta última interpretación de Gayo resulta reveladora, pues en el mundo jurídico romano las leyes eran escasas, y no se conoce una ley que haya dado origen al sacramentum. Por lo tanto, las leyes que menciona Gayo no parecen ser las leyes positivas, sino que se debe entender el vocablo leges en un sentido más amplio, como las leyes del cosmos. Así, la expresión acommodatae erant, es decir que eran acomodadas a las leyes, resulta fácilmente comprensible.

La filosofía estoica, a la que Gayo adhería, nos permite comprender el texto, pues ella sostiene la idea de un orden cósmico, y la existencia de una Lex naturae. Es a partir del pensamiento estoico, que podemos venir a entender la dimensión sagrada del sacramentum, pues los vocablos sacra mentum, hacen referencia a la afirmación o el establecimiento de algo sagrado. Y esto es así pues se denominaba sacramentum a la afirmación o juramento que realizaban ambas partes en el proceso. Distintos autores como Danz, y Girard, sostienen esta idea.

El sacramentum, también puede ser entendido como sacrificium, en el sentido de hacer algo sagrado. Esta idea se afirma en la circunstancia que, en un principio, el sacramentum comprendía el sacrificio de bestias, a las cuales se les examinaban las entrañas siguiendo una disciplina etrusca conocida como aruspicina. Para la época en que vivió Gayo, esta práctica había sido abandonada, por lo que el sentido de sacrificium, sólo podría encontrar fundamento en las prácticas más arcaicas. Esta conclusión ha sido sostenida por autores como Noailles y Lévy-Bruhl, y encuentra fundamento en la etimología, pues en el idioma osco, el vocablo sakoro significa sagrado, y sakrim, víctima del sacrificio. 
El propio Lactancio reconoce que el vocablo sacramentum no tiene un origen cristiano, y lo emplea tanto en sentido pagano como cristiano. En sus textos habla de un coeleste sacramentum, y de un Sacramenta ignis et aguae nuptiarum, con una clara alusión al matrimonio pagano. Sin embargo, va a ser el primer escritor en vincular el vocablo a la religión, como a la vez de un sacramento veritatis,

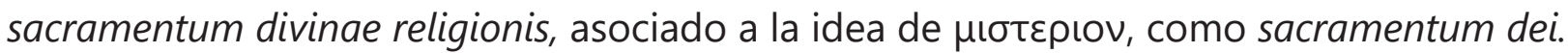

Tanto el sentido romano de sacramentum, como el cristiano, se van a mantener durante la edad media, como lo atestiguan los escritos de San Agustín, que vincula el sacramentum a la idea de sacrificium ya con sentido cristiano, y asimismo los denominados Juramentos de Estrasburgo del año 842 , en donde el sacramentum, aparece asociado a la idea de juramentum.

\section{BIBLIOGRAFIA CITADA.}

Corpus luris Civilis. Digestum Vetus seu Pandectarum luris Civilis cum lectionum Florentinarum Varietatibus. Venetiis, apud luntas, 1589

Corpus luris Civilis. Trad. García del Corral. 1889

Agustín de Hipona: De Civitate Dei. Biblioteca de Autores Cristianos. Ed. Bilingüe, Federación Agustiniana Española. Traducción de Santos Santamarta del Río y Miguel Fuertes Lanero. 2019

Aulo Gellio: Noctes Atticae. Ed. Les Belles Lettres, Paris, 2002

Catón: De agricultura. Texte établi et traduit par R. Goujard. Ed. Les Belles Lettres, 1975

Cleanthes: Himno a Zeus. Les stoiciens, La Pleiade. 1962

Cicerón: De natura deorum. Ediciones UNAM, Centro de Estudios Clásicos, Instituto de Investigaciones Filológicas, Universidad Nacional Autónoma de México, 1976

Cicerón: De Legibus. Ed. Les Belles Lettres, Paris, Texte établi et traduit par G. de Plinval. 1959

Cicerón: De Re Publica. Ed. Les Belles Lettres, Paris, Texte établi et traduit par Esther Bréguet. 1980

De Ghellinck: Pour I'histoire du mot Sacramentum, publicado por la Université Catholique et Colleges Theologiques O.P. et S.J. de Louvain, 1924

Di Pietro, Alfredo: Verbum luris. Ed. Abeledo Perrot. 1968

Di Pietro Alfredo. Ius Fasque Est. Revista Prudentia luris n I, Universidad Católica Argentina. 1980

Dúmezil, Georges. La Religion romaine archaïque, avec un appendice sur la religion des Étrusques, Payot. 1966

ELIADE M. Histoire des croyances et des idées religieuses, tome 1: de l'age de la pierre aux mystères d' Eleusis. Broché, Paris, 1989

Festus: Abrégé des Hauts faits du people romain. Ed, Les Belles Lettres, Paris 1994

Foster, Theodore. Mysterium and Sacramentum in the Vulgate and old latin versions, publicado por The American Journal of Theology - The University of Chicago Press. 1915

GAYO. Instituta, Trad. Alfredo Di Pietro, Abeledo Perrot, 5a Edición. 1997 
Heinemann F., Herkunft und Bedeutung einer Antithese im griechischen Denken des 5. Jahrhunderts, Nomos und Physis, Basel. 1987

Kaser, Max. Zur legis actio sacramento in rem. Estudios de derecho romano en honor de Alvaro D’Ors. 1987

Kaser Max, Das altrömischer “ius”. Vandenhoeck \& Ruprecht, 1949

Lactancio, Instituciones Divinas, Editorial Gredos. Madrid. 1990

Lebacqz, Georges Les derniers Anténicéens, "Pour l'histoire du mot Sacramentum" publicado por la Université Catholique et Colleges Theologiques O.P. et S.J. de Louvain, 1924

Levy Bruhl, L'âme primitive, Paris, Presses Universitaires de France. 1963

Levy Bruhl, Recherches sur les actions de la loi, Sirey, Paris. 1960

Loi, Vincenzo Per la storia del vocabolo Sacramentum: Sacramentum in Lattanzio, y II termine mysterium nella literatura latina prenicena publicado por la revista Vigiliae Christianae, 1965

Martin Albo Huertas, Lourdes. Latín pagano, lengua de cristianos. Cristianización del léxico en las Divinae Institutiones de Lactancio. Tesis doctoral. 2003

Eliade, Mircea. Historia de las creencias y las ideas religiosas, Paidós Orientalia, Barcelona. 2014

Ovidio, Publius Ovidius Naso, Ovide, Les Fastes. Les Belles Lettres., Píndaro, Fragmentos.1993

Plauto, Anfitrión. Traducción Gregorio Hinojo. Espasa Calpe, 1991

Rig Veda, Hermann Grassmann, F. A. Brockhaus, Leipzig, 1877

Sofocles, Edipo Rey, Paris, Les Belles Lettres 1958

Tito Livio, Ab urbe condita. Texte établi et traduit par Paul François. Ed. Les Belles Lettres. 2003

Varro, De lingua latina. Editorial Anthropos, Editorial del Hombre, Barcelona. 1990 